\title{
Web-Site Survey of Recent Ecomaterial Developments in Japan
}

\author{
Katsutoshi Yamada, Kohmei Halada and Kiyoshi Ijima \\ Ecomaterials Center, National Institute for Materials Science, Tsukuba 305-0047, Japan
}

One of the gravest environmental problems facing us today is how to manage materials we use and produce as a result of the industrial development in the 20th century. The concept of ecomaterials was proposed with their full life-cycle taken into consideration in 1991 and has widely developed now. There have been many governmental activities for the creation of sustainable society in Japan such as enactments of environmental laws and regulations. Many Japanese enterprises have been also engaged in a lot of activities for environmental protection. Owing to their endeavour, ecomaterials in Japan have been developed and their number has increased yearly. The research was made on how ecomaterials are currently used in Japan. All the information was obtained from the Web-sites 2004 year version environmental reports of the organizations concerned. In this paper, ecomaterials produced by two hundred and sixty six listed companies on the stock market were researched and classified into six categories. About 3900 ecomaterials were found in the 2004 year version environmental reports of 266 companies researched, whereas the number of ecomaterials researched in the year 2001 was only 1898 in 286 companies and in the year 2003 about 3700 in 281 companies. This means the number of ecomaterials in Japan in the year 2003 nearly doubled compared to that of 2001 and increased further in 2004. It also indicates the realization on the part of Japanese companies of the importance of ecomaterials resulting in the advancement of related research activities. Higher materials efficiency products of user friendly, energy saving and high performance type, which are the results of years of engineering research and development are being promoted as newly improved and efficient products. It seems that the time is approaching when it is necessary to consider as a part of environmental problems the limited availability of natural resources and to promote a sustainable society from a broader perspective.

(Received June 24, 2005; Accepted August 12, 2005; Published December 15, 2005)

Keywords: Japanese ecomaterials, classified ecomaterials, ecomaterials analysis in Japan

\section{Introduction}

In compensation for the industrial development in the 20th century, human activities have imposed upon us a big environmental dilemma. As great amount of resources have been consumed and wasted, one of the gravest environmental problems facing us today is how to manage materials we use and produce, since these materials have had sometimes unfortunate results of producing disastrous effects on mankind and the global environment.

The concept of ecomaterials was proposed ${ }^{1,2)}$ with their full life-cycle taken into consideration in 1991 one year prior to the year Rio summit was held, and has widely developed now.

At the early stage of ecomaterial development, three indices of ecomaterials were pointed out. ${ }^{2)}$

(1) Expanding human frontiers: activities of mankind in industrial and scientific developments on a global scale.

(2) Co-existence with the eco-sphere: to minimize harmful impact upon the environment.

(3) Optimizing amenities: to create a comfortable life in symbiosis with nature.

These indices are used to explain that ecomaterials are not special ones with certain characteristics or functions, but that all materials should and could evolve into ecomaterials.

Due to materials engineering, ecomaterials are being evolved from ideas into practical solutions to environmental dilemma. Halada and Yamamoto $^{3)}$ gave a good review of ecomaterials and pointed out four key types thereof, namely, "hazardous substance free material", "materials with green environmental profile (which are produced with the least possible environmental burden in their manufacturing process)", "recyclable materials", and "materials with high material-efficiency" all of which fall under the category of ecomaterials of life-cycle design.
Furthermore, two contributing fields of materials, ${ }^{4)}$ i.e. "function materials for environmental protection" and "materials for advanced energy systems", were additionally introduced as ecomaterials in a broader sense.

There have been many governmental activities for creating sustainable society such as enactments of laws and regulations for pollution control, promotion of recycling of materials, reduction of amount of wastes, and many others in Japan. And also many enterprises have been engaged in a lot of activities for environmental protection.

According to the information made public through the Web-site of the Ministry of the Environment of Japan, the number of environmental reports opened by Japanese enterprises in the year 1997 was only 169 and then it was increased to 743 by the year 2003. Especially the increase was the biggest between the year 2000 and the year 2001 from 430 to 579.

It is considered that 2001 was the year when the environmental reports became immensely and widely popular among Japanese companies. Owing to their endeavour, ecomaterials in Japan have been developed and their number has increased yearly.

However no research on the total condition and characteristics of ecomaterilas in Japan was conducted before ours.

Our research ${ }^{5-7)}$ was started in 2001 with the view of sorting out and analysing current endeavours on the part of Japanese industries for the development and manufacture of ecomaterials best suited to 'sustainable society'.

In this report, we demonstrate how ecomaterials are distributed in the market through our research into the 2004 year version environmental reports opened in the Web-sites of Japanese enterprises.

\subsection{Process of research}

Japanese companies listed on the stock market with more 
than 5000 employees were targeted and research was conducted on them through the Web-sites survey. In the process, the companies showing their environmental reports openly in the web-sites were selected for our research. In addition, several companies with less than 5000 employees which we regard as important from the viewpoint of ecomaterials were also targeted. Environmentally conscious materials were chosen from the Web-sites environmental reports of the companies and then were classified into the six categories propounded by Halada and Yamamoto. ${ }^{3,4)}$ This time, the research was performed on the 2004 year version. 266 companies were chosen and categorized into sixteen industrial groups. In each industry, average number of ecomaterials produced by a company was obtained by dividing the number of total ecomaterials in all categories by the number of companies in the industry. The ecomaterials obtained from 2004 environmental reports were compared with those from 2001 and 2003 year versions of our previous reports $^{5-7)}$ and analysed accordingly.

\subsection{Counting ecomaterials in environmental reports and Web-sites}

In 2001, Japanese ecomaterials were not yet so many as today and we considered that the number of ecomaterials referred to in the environmental reports alone did not sufficiently represent the state of ecomaterials in Japnan. Consequently in the 2001 year version research, we decided to count them not only in the environmental reports but also in the general web-sites of the organizations.

In these days, however, the importance of ecomaterials are widely recognized and their appearance in the environmental reports of Japanese organization has increased considerably, whereas, in many cases, general and commercial products are placed rather as an advertisements in their general web-sites.

Also the criteria for the recognition of ecomaterials differ from company to company which makes it difficult for us to decide the reasonable, practical and general standard for the selection of ecomaterials. In consideration of the above, in the 2003 year version, the research of ecomaterials was performed only through the environmental reports and/or the web-sites in substitution therefore or supplementary thereto. General web-sites were not researched at all.

This method has the advantage of obtaining database which can be easily traced and identified by anybody and thus will guarantee its objectivity. As a result, organizations which did not issue environmental reports were not researched. As for, organizations which did not issue environmental reports on a yearly basis, researches were performed on them only in a year when reports were issued. The same principle mentioned in the above for the 2003 version research was also applied to the 2004 version.

\subsection{Classification}

An ecomaterial was classified into one of the six categories in accordance with the way such material was applied and not with its characteristics per se. Therefore the same ecomaterial was placed in a different classification depending on a way it was used. For example, if a certain ecomaterial was used for 'increasing the efficiency' of their products in a company A, it was classified to 'higher material efficiency', whereas in case the same material was used for decreasing the burden of manufacturing process in a company $\mathrm{B}$, it was classified to 'green environmental profile'. Needless to say, a way an ecomaterial is used in a certain company can not be interpreted as exclusively suitable for one paticular classification. Generally speaking an ecomaterial has more than one function. In that case, we selected the classification most befitting to its prominent feature in order to adhere to our principle that an ecomaterial in a certain company be counted only once in our research.

\subsection{The way ecomaterials were counted in ecoproducts}

The way we counted ecomaterials differed with the types of ecoproducts for which they were used as mentioned in the below. Regarding ecoproducts produced by manufacturers and supplied to their customers, in case descriptions were given or fairly presumed to be given in environmental reports on ecomaterials used therefore, each and every kind of such ecomaterial was counted. Especially, regarding products produced by electrical and electronical industry, it was often explained that more than one type of ecomaterials were used for one ecoproduct, for example, hazardous substance free type, use-of-recycled-materials type and/or high efficiency materials type. In these cases, all types referred to were counted separately. Even though a product was referred to as an ecoproduct, in case no explanation for a definite ecomaterial used for such product was available, no material was counted as an ecomaterial.

On the other hand, as for ecoproducts introduced by manufacturers for the purpose of decreasing environmental burden in the manufacturing process of their own products, we presumed that only one ecomaterial was used for in one ecoproduct and counted accordingly. It was because, as a rule, such manufacturers did not disclose (or possess) sufficient information on ecomaterials for us to classify them accurately.

\section{Result}

The result was shown in Figs. 1 and 2. Our research into the 2004 year version environmental reports of 266 companies found references to about 3900 ecomaterials, whereas

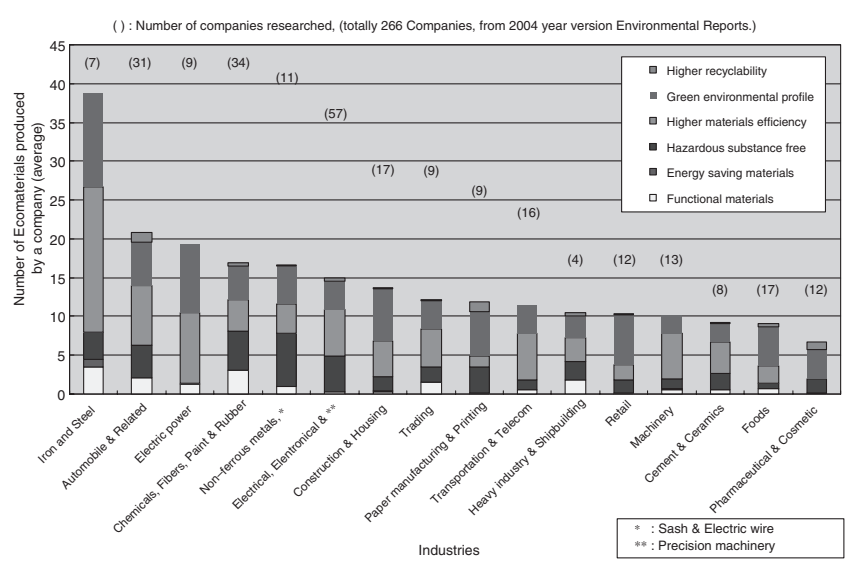

Fig. 1 Japanese Ecomaterials shown in 2004 year environmental reports of 266 companies. 


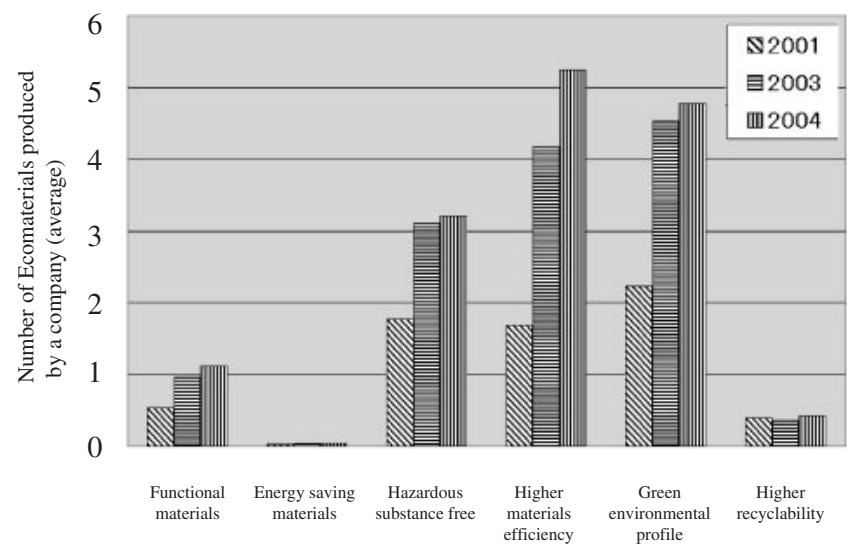

Fig. 2 Change in number of Japanese Ecomaterials from 2001 to 2004.

286 companies researched showed only 1898 such materials in their 2001 year reports and about 3700 such materials in 2003. It means that the number of ecomaterials produced in Japan has doubled in these several years. It also indicates the realization on the part of Japanese companies of the importance of ecomaterials leading to the advancement of related research activities.

This report has researched the present state of characteristics and quantity of ecomaterials by the perusal of environmental reports of manufacturers. In the process, the difficulty has arisen because of the non-uniformity in the way such reports are written due to mergers and/or consolidations of companies. For example, each company has its own rules and standards in describing ecomaterials, ecocomponents and/or ecoproducts and even in adopting its products under these categories. Some companies put several materials together into one group and refer to them as one ecomaterial and other companies enter the same material into different items and refer to it as several ecomaterals. To make the matter worse, there are companies who have altered their rules and standards from year to year.

Therefore, the number of ecomaterials mentioned in this report has no great significance individually for a particular company or a manufacturer. The number has, however, a statistical importance since it gives an over-all view on the whole activities of Japanese industries grappling with global environmental problems and is quite useful in grasping the challenge they face in this field.

We would like to point out, therefore, that sometimes the detailed discussion on an individual material based upon its number is either misleading or nonsensical.

The characteristics of the Japanese ecomaterials in each industry are as follows.

\subsection{Iron and steel industry ${ }^{8-12)}$}

The characteristics of the ecomaterials in steel industry are shown in Fig. 3. In 2004, the peculiar ecomaterials in this industry are as follows.

\section{(1) Higher materials efficiency}

High tensile strength, higher efficiency type (magnetic steel), corrosion resistant, long life and other type of increasing efficiency.

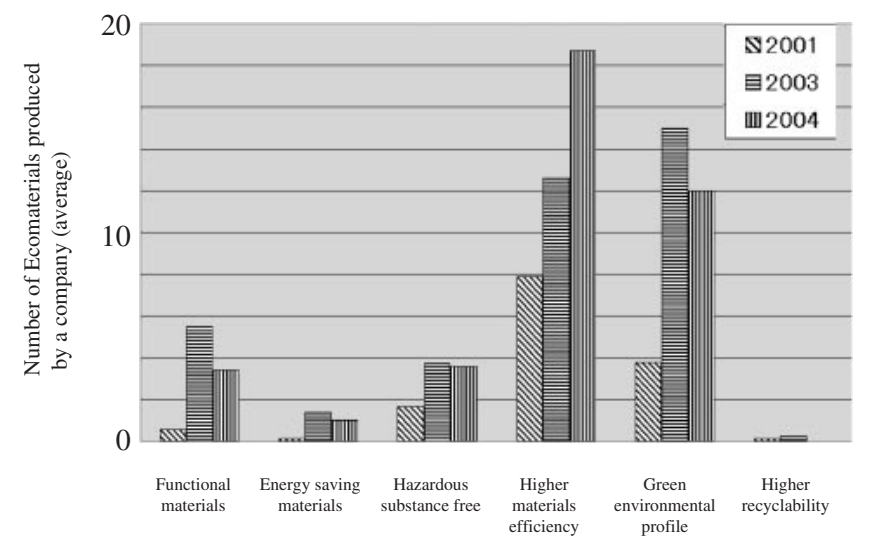

Fig. 3 Change in number of Japanese Ecomaterials in Iron and Steel industry from 2001 to 2004.

(2) Green environmental profile

'Use of recycled material' and 'reduction of burdens on the next process' (for example, precoating for the omittion of painting process in manufacturers).

(3) Hazardous substance free

Cromate free $\left(\mathrm{Cr}^{6+}\right.$ free $), \mathrm{Pb}$ free and other hazardous substances free.

(4) Functional materials

Catalysts, absorbers and other materials for improving circumference.

(5) Energy saving materials

Materials for LNG gas, generation of electric power, heat exchanger and others.

In steel industry, no recyclable type ecomaterials were found in 2004. Most likely, it was due to the generally adopted notion that steel is fundamentally recyclable.

\subsection{Automobile and related industries}

Formerly, numerous similar products were reported separately as a different individual recycling product but such references to individual products have lately decreased and now they are often put into one ecomaterial group.

Instead, new engineering developments have borne fruits in many ecomaterials and ecoproducts which are indispensable to the following automobile products

(1) low exhaust emission in diesel vehicles with the DPR and DPNR catalytic converter systems.

(2) gasoline-powered vehicles with improved fuel efficiency: materials for improved engine, power transmission and others; materials for light weight.

(3) hybrid vehicle (the combination of a gasoline engine with a separate motor has achieved high efficiency operation and realized fuel efficiency twice as high as that of conventional gasoline engine).

(4) fuel cell hybrid vehicles with more increased efficiency.

(5) clean energy vehicles such as fuel cell car and CNG vehicle.

In Fig. 4, change in the number of Japanese ecomaterials in automobile and related industry from 2001 to 2004 is shown. Functional materials such as catalytic materials have increased in 2004. In Fig. 5, we can see the characteristics of ecomaterials in automobile and related industry in these days. 


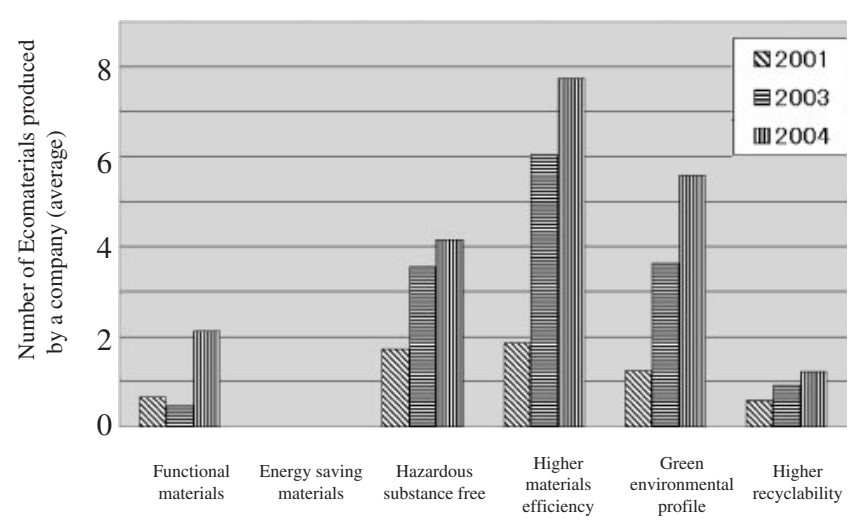

Fig. 4 Change in number of Japanese Ecomaterials in Automobile and Related industry from 2001 to 2004.

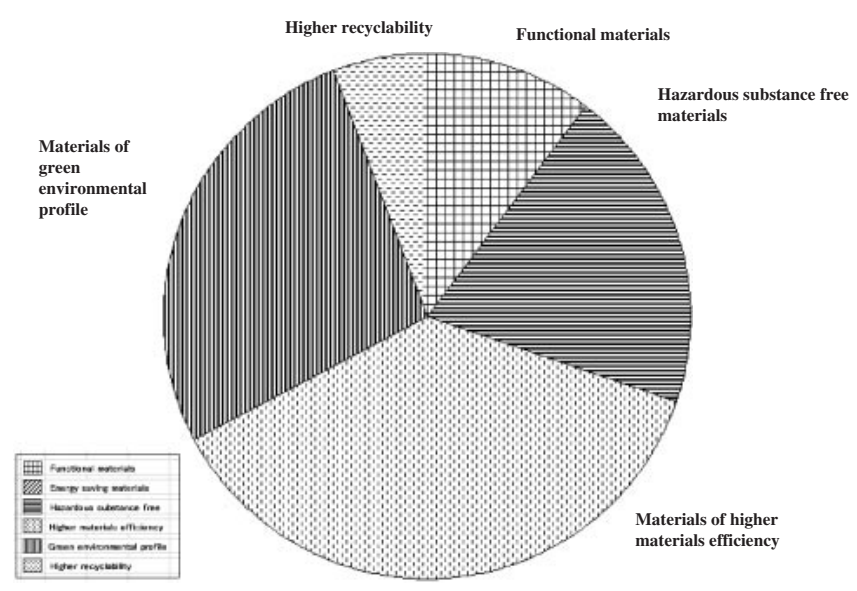

Fig. 5 Japanese Ecomaterials in Automobile and Related industry in 2004.

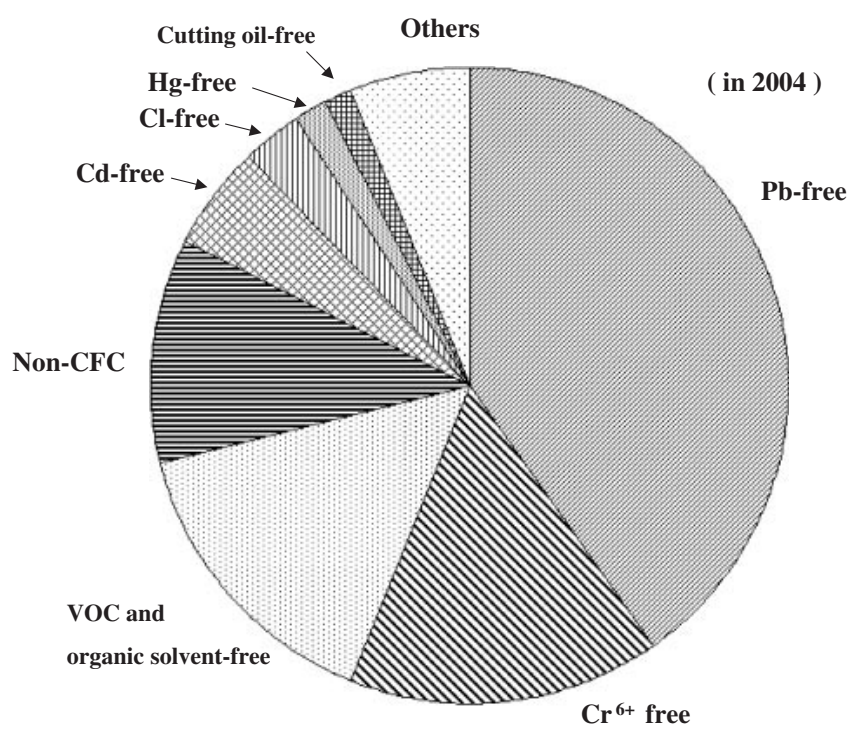

Fig. 6 Hazardous substance free Ecomaterials in Automobile and Related.

The characteristics of hazardous substance free ecomaterials are also shown in Fig. 6.

For recycling materials essential to the compliance with Law for the Recycling of End-of-Life Vehicles, there are a

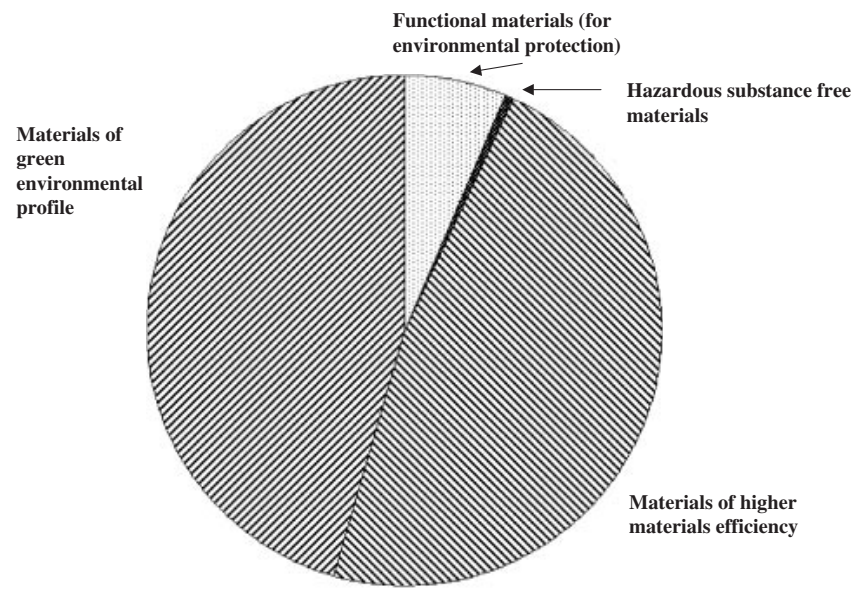

Fig. 7 Japanese Ecomaterials in Electric Power industry in 2004.

few higher recyclability type ecomaterials but most of them are green environmental profile type ecomaterials made from recycled materials.

\subsection{Electric power industry}

The ecomaterials in electric power industry are shown in Fig. 7. The essential ecomaterials are

(1) Higher materials efficiency

Materials for raising the thermal efficiency of thermal power station: Technical development and improvements, such as introducing Combined Cycle Power Generation, highly efficient Advanced Combined Cycle Power Generation and More Advanced Combined Cycle Power Generation.

Materials for reducing the rate of power transmission and distribution loss: Increasing the voltage of transmission power and adopting low-loss transforming facilities.

(2) Green environmental profile

Recycled materials such as road materials, raw materials for cement and others: Recycling of industrial waste from scrap concrete utility poles, coal ash and others.

\subsection{Chemicals, fibers, paint and rubber industry}

The ecomaterias in this industry are shown in Fig. 8. Functional materials are catalyst, absorbing materials and many other chemical materials useful for improving environment.

Hazardous substance free ecomaterials are increasing. Also higher materials efficiency ecomaterials such as higher efficiency tyres for cars to increase the energy efficiency in running and product performance are increasing.

Furthermore, many types of ecomaterials in the chemical field made from wastes and by-products (as green environmental profile ecomaterials) are also being developed. In paint industry, although the number of ecomaterials counted has not changed much, new hazardous substance free paints with excellent quality and subject to less deterioration by the passage of time have been developed year by year.

\subsection{Non-ferrous metals industry and sash \& electric wire industries}

The number of hazardous free ecomaterials and ecomate- 


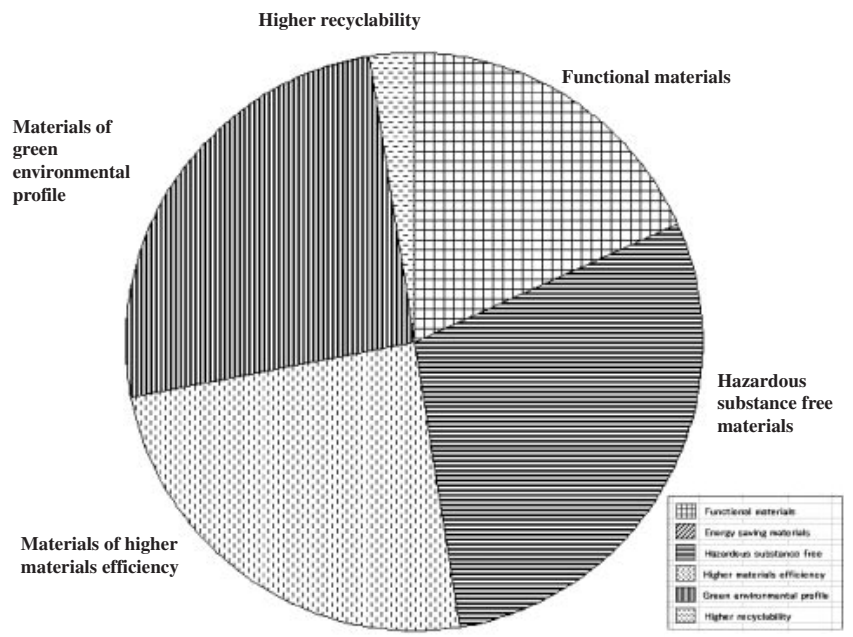

Fig. 8 Japanese Ecomaterials in Chemicals, Fibers, Paint and Rubber industry in 2004.

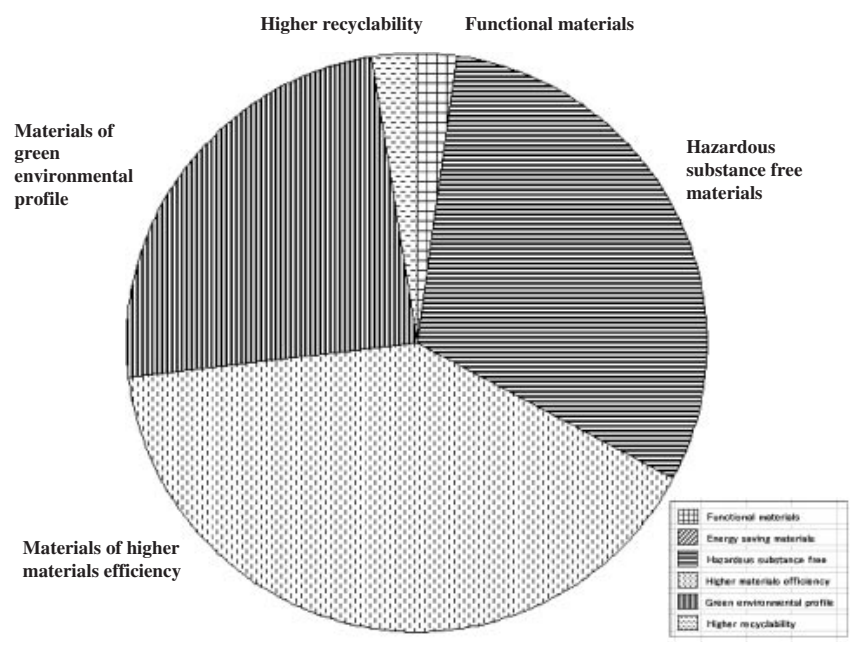

Fig. 9 Japanese Ecomaterials in Electrical, Electronical and others industry in 2004.

rials for increasing energy efficiency at home is multiplying in these days.

\subsection{Electrical, electronical and precision machinery industry}

In Fig. 9, the characteristics of ecomaterias in this industry are shown. In an effort to comply with the regulations in Europe, more and more hazardous substance free ecomaterials are being used. The use of lead-free ecomaterials is increasingly popular among manufacturers. Besides, higher materials efficiency products of user friendly, energy saving and high performance type, which are the results of years of engineering research and development are being promoted as newly improved and efficient products.

Law for the Recycling of Specified Kinds of Home Appliances in Japan has brought about the increasing use of recycled materials and materials suitable to recycling. The details on hazardous substance free ecomaterials are shown in Fig. 10.

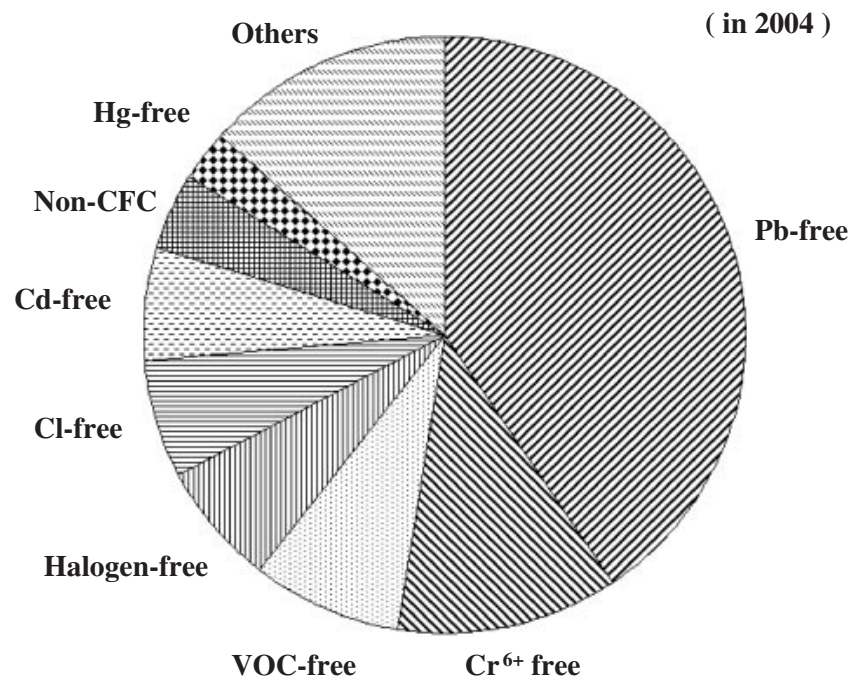

Fig. 10 Hazardous substance free Ecomaterials in Electrical, Electronical and others.

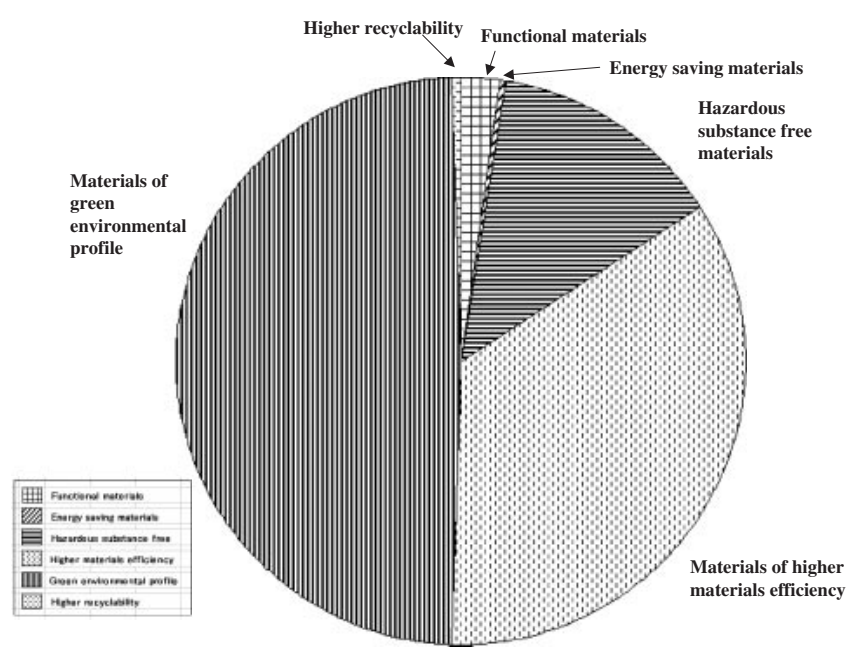

Fig. 11 Japanese Ecomaterials in Construction \& Housing industry in 2004.

\subsection{Construction and housing industry}

In response to Law for the Recycling of Construction Materials, Construction Industry is doing its utmost to find use for recycled materials in order to cut waste discharge by converting construction waste into wide variety of products.

In Housing Industry, in order to avoid sick-house syndrome, low-formaldehyde and low-VOCs type building materials have come into wide use. They have also reduced the use of other hazardous materials. In 2004 they promoted successfully the sale of environmental friendly houses approved by LCA. Faced with the situation brought about by the law mentioned in the above, the industry utilizes the two large part of ecomaterials, namely, 'materials of higher materials efficiency' (such as saving energy and long life type) and 'materials of green environmental profile' (which are the use of recycled materials). A small amount of hazardous substance free type ecomaterials are also used, as shown in Fig. 11. 


\subsection{Others}

Although not directly reflected in the number of ecomaterials, owing to the efforts made in the production process, remarkable developments have been noticed in the contribution to the improvement of environment.

The number of higher material efficiency, green environmental profile and hazardous substance free type Ecomaterials in 2003 and 2004 is nearly twice its size in 2001. However, higher recyclability ecomaterials and energy saving ecomaterials are still very small in number and, regrettably, have remained almost unchanged in the past several years. Especially the lack of various higher recyclability ecomaterials constitute a major problem to be tackled in earnest henceforth in order to build a recycle-oriented society. Reuse type and hazardous-substance-free type packaging materials and containers also increased and are used widely at logistics stage. In machinery industry, highly efficient energy saving new products and use of new ecomaterials are found. Although the number of reported ecomaterials of hazardous substance free type has shown the decrease in 2004, their actual utilization is definitely on the increase.

\section{Summary}

The number of Japanese ecomaterials in the 2004 year version environmental reports has nearly doubled compared with that of 2001. And it seems that the research activities are becoming rather well-balanced. Many higher materials efficiency ecomaterials useful for saving energy, increasing efficiency, extending the life of product and others are increasing year by year. Ecomaterials of each industry have their own characteristics according to an industry to which they belong. And each industry still has its own particular environmental subject to be tackled.

Finally, may we point out that the more we carry on research in the field of environment, the more convinced we become of the necessity of considering resource problems, such as its limited availability, as a part of environmental problems.

It seems that the time is approaching to deal with this important issue newly from a broader perspective and with birds-eye view approaches.

\section{REFERENCES}

1) Rare Metals Forum, eds., ECOMATERIAL (in Japanese), (Society of Non-Traditional Technology, Tokyo) (1991).

2) K. Halada and R. Yamamoto: Bull. Japan Inst. Metals 31 (1992) 505511 (in Japanese).

3) K. Halada and R. Yamamoto: MRS Bull. 26 (2001) 871-879.

4) K. Halada: Energy Resour. 23 (2002) 21-26 (in Japanese).

5) K. Halada, K. Yamada, K. Ijima and Y. Soeno: Mater. Trans. 44 (2003) 1237-1243.

6) K. Yamada, K. Halada, K. Ijima, Y. Soeno and M. Sano: Trans. MRSJ, 29 (2004) 1793-1794 (Proc. Symp. IUMRS-ICAM, Oct. 2003).

7) K. Yamada, K. Halada, K. Ijima and M. Sano: Proc. 6th Int. Conf. on EcoBalance, (ECOMATERIALS Forum, 2004), pp. 291-292.

8) Nippon Steel Corp.: Sustainable report 2004, (2004).

9) JFE Holdings, Inc.: JFE Environmental Report 2004 (2004).

10) Sumitomo Metal Industies, Ltd.: Environmental report 2004, (2004).

11) Kobe Steel, Ltd.: Environmental Sustainability Report 2004, (2004).
12) Hitachi Metals, Ltd.: 2004 Environmental Management Report 2004, (2004).

\section{Appendix}

\section{New type of classificasion}

As we already showed, Halada and Yamamoto propounded six categories of ecomaterials: 'Functional materials', 'Energy saving materials', Hazardous substance free', Higher materials efficiency', 'Green environmental profile' and 'Higher recyclability'.

In view of broad development and increase in number of Japanese ecomaterials in recent years, 'Ecomaterial Forum' proposed a new type of classification into six vector groups each of which has its particular direction and value regarding the reduction of environmental burden. They are 'green resource (from resources of lower impact)', 'green process (by environmental benign process)', 'performance \& efficiency (to efficient usage)', 'refreshment (to comfort the environment)', 'chemical safety (with less hazardous risk)' and 'recyclability (for sound material flow)' as shown in Fig. A.1.

In the classification of the six vectors, 'Functional materials' are changed to 'refreshment'. 'Energy saving materials' and 'Higher materials efficiency type ecomaterials' are integrated into 'performance \& efficiency'. 'Hazardous substance free' and 'Higher recyclability' are classified to 'chemical safety' and 'recyclability', respectively. 'Green environmental profile ecomaterials' are classified to either 'green resource' or 'green process' vectors, according to their charateristic.

In Fig. A.2, the 2004 version ecomaterials were classified into the above-mentioned new type of classification into the six vector groups. Each vector group indicates the judgement on the value of each characteristic it expresses by the number of ecomaterials classified into the group. The most highly valued vector is 'performance and efficiency' in 2004.

\section{About ecoproducts}

As for certain ecoproducts, it was explained in detail that

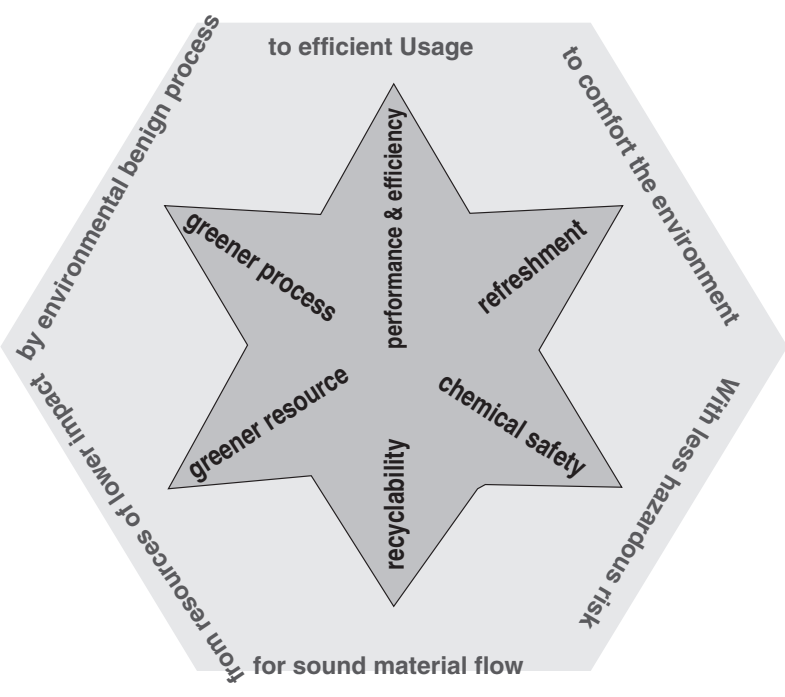

Fig. A.1 New vector type classification. 


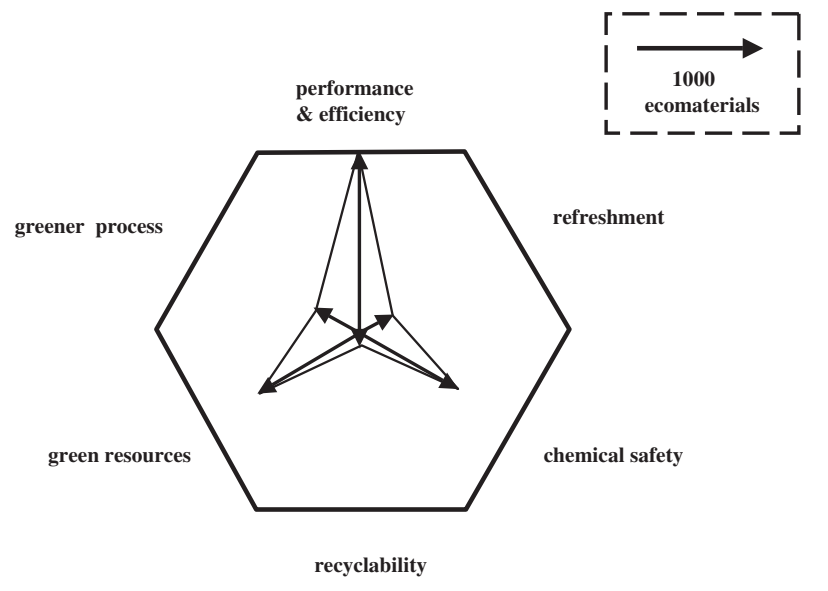

Fig. A.2 New vector type classification of Japanese ecomaterials in 2004.

several types of ecomaterils were used for them. For example, a home television set has an Pb-free ecomaterial, an energy saving LED, a recycled material for outer panel and some others. In these case, we counted all the described ecomaterials in this report. On the other hand, there are many ecoproducts which do not refer to the use of ecomaterial or ecomaterials in the environmental report, but we are certain that they had used several ecomaterials. This discrepancy makes it inevitable that our research has some limitations on the accurate review of Japanese ecomaterials at present. To ensure the reliability, accuracy and trust of our field work, we adopted the way of counting ecomaterials as described previously fully realizing the limitation incurred but confident that it was the best we could do under the circumstance, for that anybody can at least verify our statistics.
About a number of ecomaterials produced by a company Ideally, the best way to grasp accurately the present status of ecomaterials in a country is to find out the share they occupy in the total economy of the country. Based upon such findings, we can determine quantitively to what extent each ecomaterial influences environment and decreases environmental burden and thus acquire the guiding direction to be followed in the future. However, the reality is that it is still very difficult to find ideal data mentioned in the above and we had to be satisfied with the method already explained. Namely, we sought a number of ecomaterials used by each company and then passed judgement on the importance each industry places on economicals taking into consideration the size of such industry. Now that ecomaterials are broadly used in Japan, it is high time that we collected data reflecting the scale of the country's total economy in order to clarify the effect of ecomaterials on the decrease of environmental burden and determine the future direction to be pursued in order to attain our future goal.

The size of a company can be easily estimated by its total sales amount but the size of ecomaterials and ecoproducts can only be obtained through the detailed knowledge of relative sales amount. Consequently, the disclosure on the part of an individual company of the sales amount of ecomaterials and ecoproducts is essential and how to describe them henceforth in environmental reports should be the object of our future debate. We consider that the figures to be obtained by the following formula are quite effective and meaningful to the judgement on environmental problems.

'The sales ecomaterials (in amount of money or weight)'

'The total sales of related products (in amount of money or weight)'

Examples for an individual company,
(a) 'The sales of lead-free T.V. sets soled (in amount of money or quantity)'

$$
\text { 'The weight of lead-free materials sold' }
$$$$
\text { 'The total weight of related materials sold' }
$$

We can never over-exaggerate the necessity of disclosure by an individual company of the sales of ecomaterials and ecoproducts both in amount of money and weigh or quantity for the acquisition of essential data to our goal. 